D MÄLARDALEN UNIVERSITY

\title{
ENVIRONMENTAL POLICY AND MARKET STRUCTURE
}

\author{
ELIN BÄCKLUND
}

School of Business, Society and Engineering Bachelor Thesis in Economics, NAA305 Date: 2021-06-10 


\section{ABSTRACT}

The question of how to design efficient environmental policies has become one of the most important questions of our time, but finding the answer it is not easy. Simple models of environmental regulation do not take into account the complexity of real markets. One aspect that is sometimes ignored is the market structure of the regulated industry. This critical review of the literature shows that market structure can both influence and be influenced by environmental regulation and that determining the optimal environmental policy is complicated.

Keywords: environmental policy, environmental regulation, emission taxes, market structure, competition, imperfect competition 


\section{CONTENT}

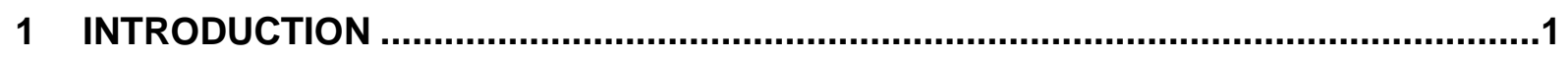

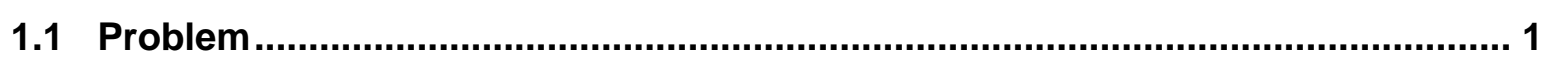

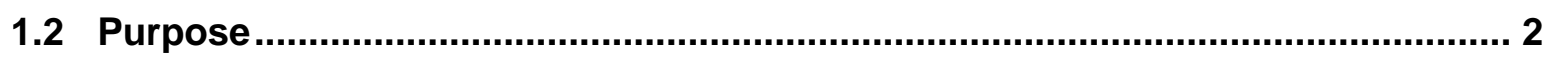

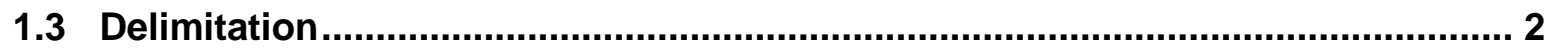

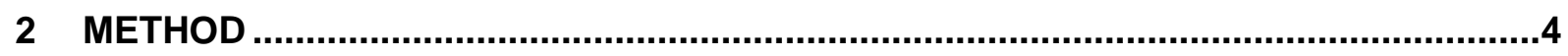

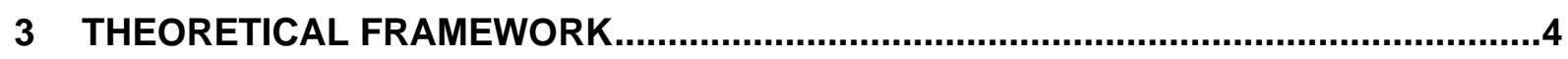

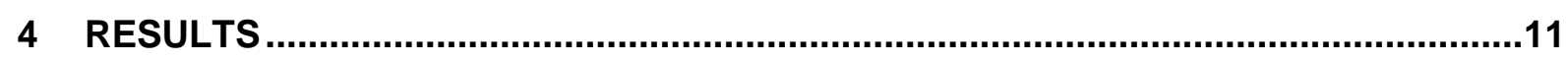

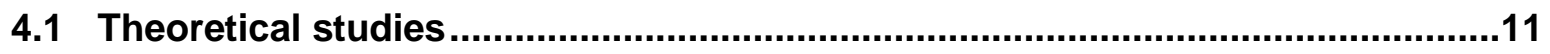

4.1.1 Emission taxes and strategy ....................................................... 11

4.1.2 Socially optimal taxation ........................................................................ 15

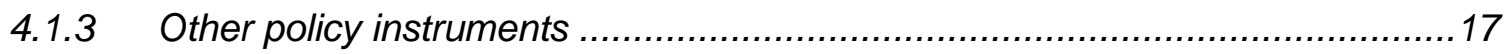

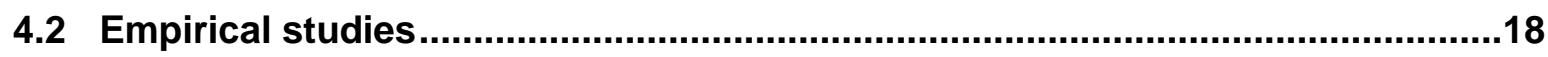

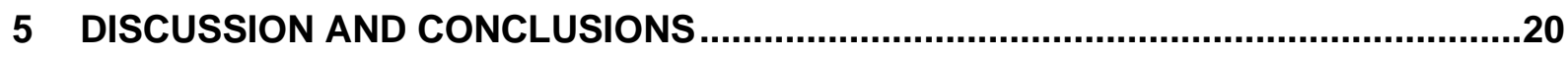

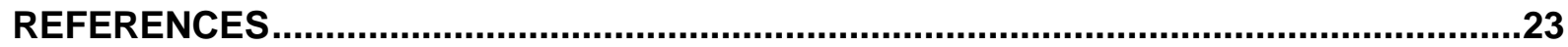




\section{INTRODUCTION}

As the negative effects of human production and consumption on the environment have become clearer and an important part of the political debate, the question of how to mitigate these effects through economic policy has become important, both politically and academically. This question is interesting because it is very complex. Policy makers must consider many different aspects of the market they are regulating in order to create an efficient policy.

Policy makers can use several different types of environmental policy instruments (Phaneuf \& Requate, 2017). Perhaps the simplest are command and control instruments like emission standards and technology standards. Emission standards limit the amount of emissions that a firm is allowed to generate, either in total or per unit of output. Technology standards mandate the firm to install production or abatement technology. However, economists usually prefer market-based instruments to command and control regulation. A common example of such an instrument is emission taxes, which require firms to pay a fee for each unit of emissions that they generate. Another policy instrument is emission permits, which require firms to buy permits to acquire the right to generate emissions. Emission permits can be distributed to firms in different ways, often through auctions or based on previous emissions from the firms. Emission permits may also be tradable, meaning that firms that have more permits than they need can sell them to firms that have too few.

As an example of an actual policy measure, Sweden became one of the first countries in the world to implement a carbon tax in 1991 (Sumner et al., 2011). Since then, carbon taxes have grown in popularity and have been implemented in many parts of the world.

\subsection{Problem}

Environmental policy generally aims to reduce the negative environmental effect of activities carried out by firms (and households). These effects are usually analysed as negative externalities. When a negative externality exists in a market, firms do not bear all the social costs of production. This makes production seem less costly than it actually is and as a result, firms produce more output than the socially optimal amount. Unless it is possible to significantly lower the environmental damage per unit of output, environmental policy that intends to counteract the negative externality will result in a reduction of output. However, 
such policies can reduce competition by making the market smaller and thus reducing the number of firms that can exist in it. This can lead to an increase in prices above the competitive level (beyond what would be reasonable given the increase in production costs) and other negative consequences of high concentration.

On the other hand, it is also possible that high concentration has positive effects. High concentration tends to decrease production, which is consistent with the goal of environmental policy, or it may have a smaller negative effect on welfare than the environmental damage has. If these positive effects can further improve the sustainability of production, the environmental policies that lead to higher concentration can be beneficial to society.

Martín-Herrán and Rubio (2018) and Phaneuf and Requate (2017) point out that pollution in a market with imperfect competition creates a situation where two market failures with opposite effects are present at the same time: the lack of competition tends to reduce output while output tends to increase under the negative externality. Any policy that aims to increase welfare must take both market failures, and the interactions between them, into account. According to Phaneuf and Requate (2017), a regulator generally needs as many policy instruments as there are market failures to reach the social optimum. With two market failures, the regulator would thus need two instruments, for instance an output subsidy and an emission tax, to incentivise the firm to both produce more and emit less. Since it is often politically difficult to impose both kinds of policies, regulators are often limited to only one, like an emission tax. The result is that only a second-best optimum can be reached, in the sense that emissions can only be at the level that is optimal given the market structure, not at the level that would be optimal in general.

\subsection{Purpose}

The aim of the thesis is to examine the relationship between market structure and environmental policy, with special focus on emission taxes in imperfect competition, through a critical review of theoretical and empirical studies on the topic.

\subsection{Delimitation}

There are many papers that examine the relationship between market structure and environmental policy from a theoretical point of view, but fewer that study the relationship empirically. Theoretical papers can provide insights into a topic even when little data is 
available, but the results rely on the assumptions about parameter magnitudes and design of the model.

This thesis reviews papers that analyse the problem from different angles and with many different methods. The aim of this review is not to provide a comprehensive survey of all the ways in which environmental policy affects market structure and vice versa, but rather to present some of the main models and results in the literature. Since there are countless ways in which a researcher could potentially study the relationship between environmental policy and market structure, this review can only cover some of them. There are many types of papers that are not covered here but that are closely related to the topic and could potentially have been included if the space was not limited.

Two of the most important factors that differ between papers is the type of regulation and the type of market structure that is studied. This review focuses on emission taxes, but since there are many other policy instruments that are also commonly used, papers that study other instruments are also included. On the other hand, most empirical papers in the review used a general measure of regulation rather than a specific policy instrument. There are perhaps even more ways to study market structure. Many theoretical papers focus on the number of firms in an industry and construct models with either a monopolist or a number of oligopolistic firms competing in the Cournot or Bertrand fashion. Some assume that the number of firms is fixed whereas others allow for entry and exit. Other papers study a different aspect of market structure, like the size distribution of firms. The empirical papers generally considered the size of firms and market entry and exit. Although this review includes several different approaches and viewpoints, there are still many others that were not included. 


\section{METHOD}

This study was conducted as a critical review of literature. A critical review of existing literature can address questions that single studies cannot. Since the aim of this thesis is to examine a topic that has many different aspects to it, it may be appropriate to use a critical review to address as many aspects as possible.

The papers reviewed in this thesis have been collected through searches in the database ABI/INFORM Global and Google Scholar. The aim has been to include papers that study the topic from different angles and with different tools to explore different aspects of the topic. All papers in the review are peer-reviewed and published in different scholarly journals. The search was conducted in English, meaning that all papers are written in English. This could potentially mean that the review excludes the findings of important papers that are written in other languages. Almost all papers were published in the last two decades. This increases the chances that the models and results are relevant and that the review does not miss important recent findings.

Much of the existing literature about the relationship between environmental policy and market structure is theoretical. These studies can investigate important questions even when there is a lack of data that can be used to answer them, making them valuable contributions to the knowledge about the topic. However, the theoretical papers are based on the assumptions that the researchers have made, and it is therefore not always obvious how the results relate to reality. Theoretical models often predict many different possibilities, but they cannot necessarily judge which of the possibilities that are most likely to occur in real markets and industries. To balance the theoretical contributions, it is useful to also include empirical research. Since the empirical research about the relationship between environmental policy and market structure is scarce, the papers included in this thesis are fewer in number and cover different aspects of the topic.

\section{THEORETICAL FRAMEWORK}

Different studies use different economic models of environmental problems. Environmental damage is usually thought of as a negative externality, meaning that it is a cost that arises due to pollution from a firm but that is not paid by the firm. The aim of environmental policy is generally to internalise this cost. However, although production generates costs for society, it also has benefits since it provides goods for consumers. If the polluting firm produces goods 
that are highly valued by society, the regulator must weigh the cost against the benefits to maximise the net effects of production. Most models include some measure of welfare that incorporates both the costs and the benefits. The benefits are often measured as consumer surplus as well as any revenue collected from the regulation, and the costs are measured using a damage function in which the costs to society increase as pollution increases. There is usually also a measure of benefits to the producer, like producer surplus or profits. In some models, other model-specific parameters are included, like fixed entry costs. Models also differ in whether firms are able to decrease the amount of emissions per unit of output through abatement or not.

One of the classical approaches to environmental policy is the Pigouvian tax, named after the early twentieth century economist Arthur Cecil Pigou (Phaneuf \& Requate, 2017). This wellknown type of environmental policy consists of a per-unit tax on emissions that is designed to reflect the costs that the emissions impose on society, with the intention of transferring these costs to the firm. The optimal level of the tax can be shown to equal the marginal damage of the emissions. However, this result is based on the assumption that the market is perfectly competitive, which is a rather unrealistic assumption for many polluting industries.

Since the classical models of environmental policy and regulation assume perfect competition, they cannot necessarily be applied to other market structures. For example, Martín-Herrán and Rubio (2018) and Schoonbeek and de Vries (2009) find that the optimal emission tax for a polluting monopolist, given that the regulator can only use one policy instrument, is not equal to the marginal damage because of the two externalities with opposite effects.

The role of the Pigouvian tax can be illustrated with a model where the market is either perfectly competitive or a monopoly, the demand is linear and the marginal private cost of production is constant. The environmental damage takes the form of a constant marginal external cost. This model can then be modified to fit other market structures and demand and cost functions with different functional forms.

The inverse demand function is:

$$
P=a-b Q
$$

The constant marginal private cost $c$ is assumed to be positive or zero. A realistic production function would probably have positive costs, but several papers reviewed here (e.g. Schoonbeek, \& de Vries (2009); Espínola-Arredondo et al. (2019)) omit regular production costs in the model since all results hold qualitatively whether they are included or not. This is also true in this model. The marginal external cost $d$, which represents environmental damage, is strictly positive. This must be the case if the environmental effect is a negative externality, 
since $d=0$ implies that there is no externality at all and $d<0$ implies that the environmental effect is a positive externality. The sum $c+d$ is assumed to be lower than $a$. If this were not the case, the optimal price would be above the highest willingness to pay and the optimal quantity would thus be zero or negative.

The socially optimal outcome is derived by maximising the expression for welfare. Welfare is defined as the sum of consumer surplus, firm profits and total tax revenue minus environmental damage. Consumer surplus is:

$$
C S=\frac{(a-P) Q}{2}=\frac{(a-(a-b Q)) Q}{2}=\frac{b Q^{2}}{2}
$$

The producer surplus equals the profits since there is no fixed cost. The tax $\tau$ is a unit tax on output that is equal to zero in the absence of regulation. Producer surplus is:

$$
P S=\pi=(P-M C-\tau) \mathrm{Q}=(\mathrm{a}-\mathrm{b} \mathrm{Q}-\mathrm{c}-\tau) \mathrm{Q}
$$

Total tax revenue is:

$$
T=\tau Q
$$

Total environmental damage is:

$$
D=d Q
$$

Total welfare is the sum of consumer surplus, producer surplus and tax revenue minus environmental damage:

$$
W=\left(a-\frac{b Q}{2}-c-d\right) Q
$$

The socially optimal welfare is obtained by maximising $W$ with respect to $Q$. This gives the expression for $Q^{*}$ below. Alternatively, the social optimum could also be reached by imposing the socially optimal price on firms. The socially optimal price should reflect the total marginal cost of production. In this model, the total marginal cost of production is the sum of the marginal private cost and the marginal external cost. The socially optimal price, quantity and welfare are therefore:

$$
\begin{gathered}
Q^{*}=\frac{a-c-d}{b} \\
P^{*}=c+d \\
W^{*}=\frac{a^{2}+c^{2}+d^{2}-2 a c-2 a d+2 c d}{2 b}
\end{gathered}
$$


The optimal price reflects the marginal social cost of production, i.e. the sum of the private marginal cost $c$ and the marginal external cost $d$.

The price, quantity and welfare in an unregulated competitive market, which ignores $\mathrm{d}$, are:

$$
\begin{gathered}
P^{c}=c \\
Q^{c}=\frac{a-c}{b} \\
W^{c}=\frac{a^{2}+c^{2}-2 a c-2 a d+2 c d}{2 b}
\end{gathered}
$$

Welfare is clearly lower in an unregulated competitive market because of the absence of the term $d^{2}$ in the expression for $W^{c}$.

The profit function for an unregulated monopolist is:

$$
\pi^{m}=P Q-c Q=(a-b Q) Q-c Q
$$

Maximising the profit function with respect to Q gives the profit-maximising output, which can then be used to obtain the monopoly price and welfare. The price, quantity and welfare in an unregulated monopoly are:

$$
\begin{gathered}
Q^{m}=\frac{a-c}{2 b} \\
P^{m}=\frac{a+c}{2} \\
W^{m}=\frac{3 a^{2}+3 c^{2}-6 a c-4 a d+4 c d}{8 b}
\end{gathered}
$$

Comparing these solutions, we see that the competitive quantity is higher than the socially optimal quantity, while the monopoly quantity can be either higher or lower. The competitive price is lower than the optimal price and the monopoly price can be either higher or lower. The optimal welfare is higher than the competitive welfare if $d^{2}>0$, which is fulfilled given the assumption that $d$ is strictly positive. However, the same is not true for a monopoly. The monopoly welfare is lower than the optimal welfare in all cases except the case where $a-c=$ $2 d$, where the monopoly welfare is equal to the optimal welfare. This can be shown by substituting $2 d$ for $a-c$ into the expressions for $Q^{*}$ and $Q^{m}$ :

$$
Q^{*}=\frac{a-c-d}{b}=\frac{2 d-d}{b}=\frac{d}{b}
$$




$$
Q^{m}=\frac{a-c}{2 b}=\frac{2 d}{2 b}=\frac{d}{b}
$$

This is the case when the unregulated monopoly already produces the socially optimal quantity at the socially optimal price.

In addition to comparing the unregulated solution to the socially optimal solution, it is also interesting to compare the monopoly welfare to the competitive welfare. It can be shown that either can be highest depending on the magnitude of the parameters. The monopoly welfare is higher than the competitive welfare if the following condition holds:

$$
d(d+2(a-c))>(a-c-d)^{2}
$$

We can see that if $d$ is close to zero, the condition does not hold and the competitive welfare is higher than the monopoly welfare. If $d$ is large, the right-hand side of the expression is close to zero (the expression within the brackets cannot be negative given the assumption that $c+d<$ a) whereas the left-hand side is relatively large, meaning that the condition does hold and that the monopoly welfare is higher than the competitive welfare. This means that, if the environmental externality is severe and taxing emissions is impossible, high concentration is preferable to low concentration since it keeps output and thus emissions low.

A regulator could use several different policy instruments to regulate the two types of unregulated markets. If the regulator chooses an emission tax to bring the quantity produced to the optimal quantity, the size of the tax will be different in the competitive market and the monopoly since the respective equilibrium quantities are different. In the competitive case, firms will produce the quantity demanded when the price equals the marginal cost. To make the firms produce the optimal quantity, the tax must raise the total marginal cost to the optimal price, $c+d$. This can be achieved by simply setting the unit tax $\tau$ equal to $d$.

In the case of a monopoly, determining the optimal tax is more complicated. The quantity produced by the monopolist can be either higher than or lower than the optimal quantity. To induce the firm to produce the optimal quantity, the tax may have to be negative, making it a subsidy instead. This is the case when the unregulated monopoly is already producing less than the optimal amount. The first-order condition for profit maximisation for a monopolist when there is a per-unit emission tax is:

$$
\pi^{\prime}=a-2 b Q-c-\tau=0
$$

Thus, the profit-maximising quantity for a regulated monopoly is:

$$
Q^{m r}=\frac{a-c-\tau}{2 b}
$$


Setting $Q^{m r}$ equal to $Q^{*}$ to induce the monopolist to produce the socially optimal quantity yields the optimal emission tax:

$$
\tau^{m}=2 d+c-a
$$

This tax is less than $d$ if $a>c+d$, which is always true given the assumption above. This result is consistent with the reasoning of Martín-Herrán and Rubio (2018) and Schoonbeek and de Vries (2009). The tax is zero if $d=(a-c) / 2$. This is true in the special case where the monopoly output is equal to the optimal output. If $d<(a-c) / 2$, the tax is negative because the monopoly originally produced less than the optimal output. In general, the optimal tax is high if the emissions have a strong negative effect on the environment and low or negative if the effect is smaller.

This model assumes that one unit of output yields a fixed amount of pollution. While this is not unreasonable to assume, it does not account for the possibility of abatement. If abatement is possible, firms can install some technology that can reduce the amount of pollution that they release into the environment without having to reduce output. There are several different approaches to modelling abatement in the papers reviewed here. For example, Conrad and Wang (1993) assume that there is a positive and increasing marginal cost of abatement whereas Espínola-Arredondo et al. (2019) assume that firms must pay a fixed cost to acquire the abatement technology that then permanently decreases the amount of pollution per unit of output.

One way to modify the model above to include abatement is to introduce the variable $A$ that represents the amount of abated pollution. Assume that one unit of output causes one unit of pollution, but a firm can choose to abate $A$ units to lower its pollution and thus its tax payments. The amount of pollution generated from the firm is then $Q-A$, which means that the tax payments of a firm now depend on $Q-A$ rather than $Q$. The cost of abatement is:

$$
C(A)=A^{2}
$$

The marginal abatement cost is:

$$
C^{\prime}(A)=2 A
$$

Under these conditions, the cost function for each firm is:

$$
C(Q, A)=c Q+\tau(Q-A)+A^{2}
$$

A competitive firm sets its price equal to the marginal production cost, which under an emission tax is equal to $c+\tau$. Precisely as in the case of the regulated competitive market above, the price is equal to the socially optimal price. Because of this, output is also socially optimal. 
Firms choose the amount of abatement that minimises the cost function above. Differentiating the cost function and setting it equal to zero gives:

$$
2 A=\tau
$$

The firm will abate its pollution until the marginal cost of abatement equals the tax rate. This is because abatement is relatively cheap at low amounts of pollution, making it more profitable to abate pollution than to let it out into the environment and pay the emission tax. At high levels of pollution, abatement is relatively expensive and it is more profitable to pollute and pay the tax. The point where it is no longer cheaper to abate than to pollute, and the firm will choose to stop abating its pollution, is when the marginal abatement cost equals the tax rate. Although this this result was derived for a competitive firm, it is also true for a monopolist. This effect arises because the tax rate is constant whereas the marginal abatement cost is increasing. If the marginal abatement cost were also constant, the firm would simply either abate all emissions or none at all. If the marginal abatement cost were higher than the tax, it would always be cheaper to pollute than to abate. If the marginal abatement cost were instead lower than the tax, it would always be cheaper to abate.

Bailey and Thomas (2017) distinguish between two theories of regulator behaviour used in the literature. The first model, the public interest model, assumes that the regulator maximises welfare in society and that regulation can counteract market failures. The second model, the public choice model, instead assumes that politicians act in their own self-interest and that the regulation that they enforce does not necessarily maximise general welfare. This model allows for regulation to benefit firms in the market since firms can influence the policy choices that politicians make.

These two ways of modelling the behaviour of regulators is important for the relationship between environmental policy and market structure. If regulators maximise welfare, environmental policy will lead to socially optimal outcomes. On the other hand, if regulators have personal motives, firms may have the ability to manipulate environmental policy to their advantage. Firms generally benefit from increased concentration, which means that they have an incentive to influence regulators to implement policies that decrease competition in the market. This model may imply that strict environmental policy causes higher concentration in a way that is not desirable for society. 


\section{RESULTS}

This section presents the results of the literature review, beginning with the theoretical papers and ending with the empirical papers.

\subsection{Theoretical studies}

This section describes theoretical studies, by presenting the models and assumptions they use, as well as their findings and how they relate to the models and assumptions. The focus here is on imperfect competition.

\subsubsection{Emission taxes and strategy}

There are several ways in which researchers have studied the relationship between environmental policy and imperfect competition. Some authors (Conrad and Wang (1993); Schoonbeek and de Vries (2009); Espínola-Arredondo et al. (2019); Montero (2002); Coria and Kyriakopoulou (2018)) have studied how environmental policy can affect market structure and how firms can use it as a strategic tool to compete in the market. A possible weakness in these papers is that they all assume that the regulator can only use one policy instrument at a time, even though there is more than one market failure. As mentioned above, the regulator would need as many policy instruments as there are market failures to reach the first-best optimum. The authors do not discuss whether this is a realistic assumption or how the introduction of additional policy instruments would affect the results of the analysis.

Conrad and Wang (1993) analyse the effects on different market structures when there is an emission tax and a cost of reducing emissions. They only consider the effects on the market, like the effects on prices and quantities, not the effects on welfare. In the model, there is one production input that causes emissions whose price consists of a basic price, the cost of abatement and the emission tax. The abatement cost is increasing and convex. The firms choose the amount of abatement that minimises the price of the input. This means minimising the sum of emission taxes and abatement costs, like in the model above. A low amount of emissions causes lower tax payments but higher abatement costs, and a high amount of emissions causes lower abatement costs but also higher tax payments. The total costs are convex and depend on the input price and the amount of output.

The emission tax has different effects in different market structures. In the analysis of a perfectly competitive market, industry profits are zero regardless of the tax, and industry output and firm output decrease when the tax increases. In the analysis of an oligopoly with no entry or exit, an increase in the tax causes a reduction of both firm and industry output, making 
the industry more collusive. It also reduces industry emissions. The effect of an increase in the tax on profit is ambiguous. An increased tax will increase prices and lower the quantity demanded. It is possible that profits increase as a result of the increased tax if the increase in revenue from the price increase is enough to offset the increased costs, but it is also possible that profits decrease.

While taxes reduce output in the industry and thus tend to decrease competition, Conrad and Wang show that subsidies on abatement can have the opposite effect. When all other variables are held constant, an increased subsidy lowers production costs which in turn increases output. This is true for every market structure considered in the paper, i.e. both in the competitive and non-competitive cases. In perfect competition, this can lead to an unexpected effect: a high abatement subsidy causes lower costs and higher output, but because of entry it can potentially increase total industry emissions. This is because the cost reduction makes production more profitable, which may cause enough new firms to enter the market that emissions increase despite the increase in abatement. Although emissions per unit of output will always decline with the subsidy, the increase in total output may offset this effect. The authors argue that countries should generally impose emission taxes rather than abatement subsidies to ensure that the policy fulfils its purpose.

Schoonbeek and de Vries (2009) conduct a similar study, but their model instead assumes that there is no abatement and only two firms. They focus especially on the circumstances in which the preferences of the welfare-maximising regulator align with the preferences of an incumbent firm. The researchers argue that environmental control measures can benefit existing firms in an industry. Although emission taxes increase costs for firms and thus decrease profits, the possible changes in market structure can offset this. When environmental policy acts as a barrier to entry, the incumbent firms may gain more from the lack of competition than they lose from the effects of the policy. The researchers create a theoretical model where there is an incumbent firm and a potential entrant in a situation where production causes a certain amount of emissions per unit and a tax is imposed to maximise social welfare. There is no abatement, meaning that the only way to decrease emissions is to reduce output. The potential entrant must pay a fixed entry cost to enter the market, and this cost is included in the welfare measure. Because of this, entry is only good for social welfare if the benefits of the consequent increase in competition are larger than the fixed cost.

Schoonbeek and de Vries find that there are many possible outcomes depending on the parameters of the model. Interestingly, they find that there are some circumstances under which both the incumbent firm and the regulator would prefer a high tax. If the entry cost of the potential entrant is high or the marginal damage is high, both the regulator and the incumbent firm prefer monopoly with a relatively high tax. The firm benefits from the tax as it 
causes the potential entrant not to enter the market, which allows it to keep a high price and low output. The regulator benefits since the low degree of competition keeps output and thus emissions low enough that it outweighs the effect of the high price and low output. This is an example of a situation where the increase in concentration as a result of the environmental policy is not enough to offset the positive effects of the policy.

In cases where the preferences of the firm do not align with the preferences of society, it is still possible that the regulator chooses to implement the policy that benefits the firm if it is possible for the regulator to stray from the objective of maximising social welfare. A monopolist could potentially be willing to spend a lot of resources on attempting to influence public policy to keep its monopoly profits.

Some papers study incentives to invest in innovation under environmental policy in imperfect competition. Espínola-Arredondo et al. (2019) analyse situations in which a monopolist faced with an emission tax can deter entry by a potential entrant by choosing whether to invest in green technology. In the model, the firms can acquire the green technology by paying a fixed cost and the entrant must pay an additional fixed cost to enter the market. The regulator chooses a tax per unit of emission with the intention to maximise welfare. The green technology that the firms can invest in lowers the amount of emissions per unit of output, which in turn lower tax payments.

The researchers analyse two main questions: whether the potential entrant enters or not and which of the firms, if any, invest in the green technology. They show that many outcomes are possible: the entrant may enter regardless of the incumbent's choice, it may choose not to enter regardless of the incumbent's choice or it may enter depending on the incumbent's choice. The outcome depends on the costs of entry and the cost of the green technology. In general, the entrant enters if the entry cost is low enough and invests in green technology only if the cost of it is low enough. If the incumbent firm invests in green technology, the combinations of costs that result in entry are fewer, meaning that the incumbent firm can in some situations keep its monopoly status by investing in green technology. This is because if the entrant enters without the green technology that the incumbent firm has, it will have a disadvantage relative to the incumbent firm since it will have to pay lager emission tax payments. This will make it less profitable to compete against the incumbent firm. To remove the cost disadvantage, the entrant must buy the green technology on top of what it already paid to enter the market, which also lowers profits.

The researchers consider two versions of the model: one where the emission tax is determined before the firms make their decisions and one where the emission tax is determined later. In the version of the model where the regulator chooses the emission tax after the number of firms 
has been established, the regulator can strategically choose the tax to reach the optimal output given the emissions in that situation. On the other hand, a regulator that is unaware of the effects of the emission tax on market structure will set fees that result in socially suboptimal levels of emissions and competition. The authors argue that policy makers should analyse the potential changes in competition that environmental policy may cause to ensure that those changes do not have negative effects on welfare.

Montero (2002) also studies investment in green technology in relation to emission taxes and imperfect competition, but he focuses on firms' decision to invest in developing technology that reduces abatement costs. Montero's model also differs from the model in EspínolaArredondo et al. (2019) in that the number of firms is fixed at two, i.e. that deterring entry is not possible, and in that a firm can to some degree take advantage of technological developments by its competitor.

Montero analyses firms' incentives to invest in environmental innovation under a variety of different market structures and policy instruments. Firms compete in either a Cournot duopoly or a Bertrand duopoly that allows for differentiated products. Firms are symmetric and there is a per-unit cost of abatement. The regulator intents to limit total emissions to a certain level and uses either an emission tax, an emission standard or emission permits to do so in different versions of the model. After the regulator has decided on the optimal policy given the current market structure and the current abatement technology, firms can invest in R\&D at a fixed cost to reduce compliance costs. Because the regulator acts before the firms, the policy that is chosen is not necessarily optimal after the firms have been able to react to it. R\&D investment lowers the per-unit abatement cost and the innovation carried out by one firm may benefit the other, that is, firms may not be able to prevent the results of their research from being used by others. The researcher finds that, in a Cournot duopoly, either emission standards, emission taxes or emission permits can give the most incentives to invest in R\&D. In a Bertrand duopoly, taxes have larger incentives than emission standards.

Much of the literature regarding environmental regulation and market structure study the ways in which the number of firms affects and is affected by environmental regulation. However, these studies generally assume that firms are symmetric, which is not always the case in reality. An important aspect of market structure and competition is the size distribution of firms. Coria and Kyriakopoulou (2018) study the effects of different types of environmental policy on the size distribution of firms. Their model assumes a two-factor production function where one input factor, energy, causes emissions. There is no abatement, meaning that the only way to reduce emissions is to reduce production or reduce the ratio of energy use to the other input factor. The energy efficiency varies across the firms and ranges from a minimum level to a maximum level, which causes the firm sizes to vary since efficient firms can grow 
larger than less efficient firms. There is also a fixed cost, meaning that production has increasing returns to scale.

The researchers find that profits are negatively affected by an emission tax for all firms. However, the percentage change in the profits is larger for small firms than for large firms. Emission standards have the opposite effect: the percentage change in profits is larger for large firms than for small firms. This is because the standard in the model is uniform across firms, meaning that large firms that emit more must reduce their emissions more. A performance standard, which limits emissions per unit of output rather than total emissions, has the same effect on different firm sizes as an emission tax. However, emission taxes affect the percentage change of profits of large firms more than performance standards do.

Different policy instruments also have different effects on the lowest efficiency a firm can have while still having positive profits. Emission taxes create a higher minimum efficiency than do performance standards, and both create minimum efficiencies that are above the one in the absence of regulation. Uniform emission standards do not change the minimum efficiency because the least efficient, and thus smallest, firms are likely not affected by the standard since they already emit relatively little.

\subsubsection{Socially optimal taxation}

The studies reviewed above analysed the effect of environmental policy on market structure and how firms can use environmental policy strategically to gain an advantage in an imperfectly competitive market. They found that emission taxes may be profitable for oligopolists, that high concentration caused by emission taxes may be both socially optimal and optimal for firms, that investing in green technology to comply with environmental regulation may decrease competition and that different policy instruments have different effects in R\&D investment in a duopoly. In addition to this, it is also important to know what the optimal tax policy consists of and how it relates to the standard Pigouvian tax. There is a lot of literature on optimal taxation in general, some of it dealing with emission taxes under imperfect competition. Researchers have studied optimal emission taxes in non-competitive markets in different types of models. The examples mentioned here study stock pollutants and durable goods.

Runkel (2004) studies the optimal emission tax in a non-competitive durable goods industry. He argues that this is an important case to study since many polluting US industries are concentrated and sell durable goods, like the car industry. In the model, there is either one firm acting as a monopolist or a fixed number of firms competing in a Cournot oligopoly. Each firm chooses an average durability for their products that decides the fraction of the goods 
produced in one period that can still be used in the next period. The durability affects the firms' costs and consumers are indifferent to products with different durability, so they are not willing to pay more for a more durable product. The cost function is convex and increasing in durability, meaning that increasing durability becomes more expensive the higher the durability is. Environmental damage is proportional to the amount of waste at the end of the product's life. This means that firms can decrease the amount of waste by increasing durability, since this decreases the number of new products that must be produced to satisfy consumer demand. With these conditions, firms have an incentive to both limit production to maximise profits and to increase production to "steal" future sales from competitors. Because firms can choose the durability of their product, they also have an incentive to keep durability low to increase future sales. The researcher finds that the optimal emission tax in both periods is equal to the marginal damage plus some other terms which can be either positive or negative. Therefore, the optimal tax can be either below, above or equal to the standard Pigouvian tax.

Many models of environmental policy only consider pollution during a single period. However, many pollutants stay in the environment for a long time and affect social welfare for many periods. For example, Lieb (2004) mentions carbon dioxide and waste as two of the most important stock pollutants that stay in the environment for many decades. He also points out that there are many pollutants that stay in the environment for a few days or months that can be considered stock pollutants in the short run but flow pollutants in the long run. Some of these are sulphur dioxide $\left(\mathrm{SO}_{2}\right)$, nitrogen oxides $\left(\mathrm{NO}_{\mathrm{x}}\right)$ and carbon monoxide $(\mathrm{CO})$.

Martín-Herrán and Rubio (2018) study the first-best and second-best tax policy for a monopolist when abatement is possible. Their model assumes a stock pollutant, meaning that the pollution created during each period accumulates and that the pollution stock decays at a certain rate. This assumption means that pollution in one period depends not only on the pollution generated in that period, but also pollution generated previously. Social welfare depends on the pollution stock, which means that it depends on both current and earlier pollution. The regulator maximises the present value of social welfare. In the first version of the model, the regulator can use both an output subsidy and a pollution tax to mitigate the two market failures. The researchers show that the regulator can reach the first-best optimum in this case. However, the pollution tax is not equal to the standard Pigouvian tax but rather the difference between the social valuation and the private valuation of the pollution stock.

In the second version of the model, the regulator cannot use both a pollution tax and a subsidy because of political constraints, so only the pollution tax is used. Here, the regulator can only reach the second-best outcome. The tax in this case is lower than in the first case since it must decrease pollution without decreasing output too much. In both the first-best and second-best version of the model, it is possible for the emission tax to be negative. A negative tax would 
mean that the monopolist receives money for each unit of pollution, which turns the tax into a subsidy. This is the case when the pollution stock is low and thus does not affect welfare much.

\subsubsection{Other policy instruments}

Economists usually prefer market-based policy instruments to emission standards. However, many countries still use the latter kind of policies despite the criticism against it, which makes it important to study these policies as well (Lin \& Pang, 2020). Lin and Pang study emission standards when the regulator cannot accurately monitor emissions. They create a model where the regulator sets a maximum amount of pollution per unit of output and inspects the firms to make sure they follow the regulation. However, firms are opportunistic and do not comply with the rules unless they find it profitable to do so. The firms choose the amount of emissions that maximise expected profits, taking into account both the cost of reducing emissions and the probability of passing the inspection. The regulator can choose how intensely to inspect the firms to increase the probability of discovering violations of the emission standard, and more intense inspection makes firms abate more and pollute less per unit of output.

In the case of a monopoly, Lin and Pang find that the firm will comply if the emission standard allows a large amount of emissions (and thus is possible to reach with only a little abatement) or if the inspection intensity is high. In the case of an asymmetric duopoly where the two firms generate different amounts of emissions per unit of output, the firm that generates the least emissions will abate more. This is because it is relatively likely that the other firm fails the inspection and is forced to exit the market. This increases the firm's profits since it will be able to act as a monopoly, so the firm finds that it is worth spending more on abatement to increase the chances of being allowed to continue to operate in the market.

Reichenbach and Requate (2013) analyse the effects of emission permit trading on competition and market structure. They find several theoretical possibilities for firms to either exercise market power on the permit market or raise rivals' costs to decrease competition on the output market. A large firm that is a net seller of permits can potentially keep the supply of permits low and prices high, just like a monopolist in any market. Similarly, a net buyer of permits can act as a monopsonist and buy less at a lower cost. Firms can also influence competition on the output market through strategic behaviour on the permit market. One possible strategy for a large firm is to buy a large share of the permits available on the market and thus cause some smaller or less efficient firms to find it more profitable to sell all of their permits and leave the output market. Another possibility for a large and relatively clean firm with less clean competitors is to "hoard" excess permits instead of selling them. This lowers the supply of permits for the competitors with less clean technology, which forces them to either abate more, which is comparatively more costly for them, or reduce output. Both alternatives tend to 
decrease the market share of the competitors. By doing this, the firm foregoes revenue from selling permits, but at the same time it gains a larger market share which may increase revenue enough to offset the initial effect.

Reichenbach and Requate also point out that the risk of this kind of abuse of permit trading schemes may be low in reality. In many circumstances, firms are unlikely to be able to significantly affect competition through their behaviour on the permit market. For example, many trading schemes, like the European Union Emission Trading Scheme, cover many firms in many industries, so a firm that has a large market share in its output market does not necessarily have an equivalent share in the permit market.

\subsection{Empirical studies}

An empirical study by Helland and Matsuno (2003) indicates that regulation that forces firms to invest in abatement technology can decrease competition because it acts as a barrier to entry. The study analyses the relationship between the cost of complying with environmental regulation and a measure of economic rent for different firms over time in the US. The researchers find that the compliance costs had no effect on overall industry profits. However, the results are different when they divide the firms into groups depending on size. The largest $25 \%$ of firms had an increase in their market value relative to their book value as a result of stricter regulation, which suggests that they were able to raise profits and exercise more market power. The corresponding value for the remaining $75 \%$ of firms did not change, implying that those firms were not able to extract economic profits like the larger firms. The researchers argue that their results indicate that environmental policy may create more concentrated industries.

The main result of this study, that environmental policy can increase concentration, is consistent with much of the theoretical literature reviewed above. Most importantly, EspínolaArredondo et al. (2019) show that environmental compliance costs can allow firms to exercise more market power than they would otherwise. Schoonbeek and de Vries (2009), who also consider environmental policy as a barrier to entry, also find that environmental policy can benefit existing firms by creating excess profits.

Bailey and Thomas (2017) study the relationship between regulation and firm creation and employment growth. They measure regulation by using an index of regulatory intensity that includes environmental regulation, but also other kinds of regulation. They find that increased regulation lowers entry by new firms and lowers exit by large incumbent firms. The negative relationship between regulation and firm creation is significant for firms overall and for small 
firms, but not for large firms. The negative relationship between regulation and firm exit is only significant for large firms. This indicates that regulation may benefit large incumbent firms in an industry since it decreases the risk of going out of business while also keeping potential entrants out of the industry. While small firms do not seem to be less likely to exit the industry when regulation increases, they may still benefit from the overall decrease in entry. The researchers argue that regulators should consider the effects of regulation on firm creation when designing new policies.

This study provides direct evidence of entry deterrence as a result of environmental policy, which has been studied theoretically by Espínola-Arredondo et al. (2019) and Schoonbeek and de Vries (2009). These results are consistent with the theoretical literature, as well as with the findings of Helland and Matsuno (2003). Although Bailey and Thomas (2017) study entry and exit whereas Helland and Matsuno (2003) study economic rent, these two variables have a lot in common. If environmental policy increases concentration, it is reasonable that entry and exit would decrease at the same time as profits increase due to stricter environmental policy. Thus, it is natural that the two studies have similar conclusions.

While Helland and Matsuno (2003) and Bailey and Thomas (2017) find that regulation generally benefits large firms, there is also evidence that compliance costs are more burdensome for large firms than for small firms. Becker et al. (2013) study pollution abatement costs as a share of the value of output for US manufacturing firms from 1974 to 2005. They note that there are several possible relationships between abatement cost intensity and firm size. If compliance with environmental regulation involves large fixed costs, the abatement cost per unit of output should be higher for small firms than for large firms. However, policies are often designed to affect firms of different sizes in different ways. For example, some policies are specifically targeted at large firms or are explicitly less stringent for small firms. If this is the case, abatement cost per unit of output may be higher for large firms than for small firms.

The researchers find that abatement costs per unit of output rise with firm size. They use a few different techniques and model specifications to account for different issues in the data, but they consistently find a positive relationship between abatement cost intensity and firm size. The researchers also note that the study does not consider the effects of regulation on market entry and exit. Regulation is sometimes more stringent for new facilities, which affects the decision to enter the market. Although existing small firms do not seem to be negatively affected by regulation, it is possible that new small firms choose not to enter because of the regulation. The entry-deterring effect of environmental regulation has been shown theoretically by e.g. Schoonbeek and de Vries (2009) and Espínola-Arredondo et al. (2019) and empirically by Bailey and Thomas (2017). It is also important to note that, although costs may rise because of regulation, regulation can still benefit firms. Conrad and Wang (1993) show 
theoretically that it is possible that increased costs in the form of emission taxes in an oligopoly increases profits.

Ryan (2012) studies the welfare effects of regulation of the US cement industry between 1980 and 1999. During this period, environmental legislation increased compliance cost for existing firms in the industry. It also affected potential entrants that had to pay a sunk cost to acquire the necessary certifications to build a new production plant. The researcher studies the cost structure of the industry before and after the implementation of the regulation to estimate the effects of the regulation on the market. He claims that cost analyses for environmental regulation often only include the cost of controlling and monitoring firms, not the potential welfare loss of increased industry concentration. This is a problem because an increase in compliance costs often cause an increase entry costs, which tends to increase concentration, and many polluting industries are already highly concentrated. One of the main findings of the study is that regulation increased the entry cost in the industry. This contributed to a significant welfare loss to consumers because it increased concentration.

\section{DISCUSSION AND CONCLUSIONS}

The relationship between environmental policy and market structure is complicated and can be viewed from many different angles. Non-competitive market structures can both be influenced by and influence the effects of environmental policy.

One of the most important differences between firms in perfect competition and firms in noncompetitive markets is that non-competitive firms can employ different strategies to gain an advantage towards their competitors. Firms in perfect competition have less freedom to vary output, prices and other variables like investment decisions. Since the strategic behaviours that characterise non-competitive firms generally make the market less efficient, regulating such firms is more complicated than regulating perfectly competitive firms.

Many of the papers reviewed here study the ways in which environmental policy can influence market structure and be used strategically. An important finding is that environmental policy can sometimes act as a barrier to entry and thus make an industry more concentrated. It also tends to reduce industry output and raise prices, possibly in a way that increases profits. In some circumstances, incumbent firms can strategically influence the effect of environmental policy on market structure. For example, there is theoretical evidence that a monopolist can potentially deter entry by investing in abatement technology, that a firm may spend more on 
abatement if doing so will allow the firm to operate in a less competitive market and that firms can use environmental policy to raise their competitors' costs.

Environmental policy can also affect concentration by having different effects on firms of different sizes. A policy that benefits large firms and allows them to grow further will tend to increase concentration, and a policy that benefits small firms will decrease concentration. Several studies reviewed here provided evidence of environmental policy having different effects on firms of different sizes. Empirical evidence shows that environmental regulation can benefit large firms and leave smaller firms mostly unaffected. This may increase concentration since profitable firms have more resources to devote to capturing a larger market share. Theoretical evidence shows that regulation always lowers profits but that different policy instruments can have different and even opposite effects on firms of different sizes. Emission taxes have, like the empirical evidence shows, a larger negative effect on small firms than on large firms.

While environmental policy can affect market structure, market structure can also influence the effects of environmental policy. Several papers reviewed here study the optimal environmental tax in a non-competitive industry. Perhaps the most crucial result is that the socially optimal emission tax is not necessarily equal to the marginal damage, which would be the case if the tax were a standard Pigouvian tax. Using different models, researchers have found that the optimal emission tax may be above, below or equal to the standard Pigouvian tax. In most models, the optimal tax is lower than the marginal damage. This is because of the double market failure: output tends to increase given the negative environmental externality whereas the imperfect competition tends to reduce output. However, market structure is not always the only reason why the optimal tax is not equal to the marginal damage. Sometimes (like in Martín-Herrán and Rubio (2018) and Runkel (2004)) there are assumptions about the production or the environmental damage that also contribute to the deviation of the tax rate from the marginal damage. It is also important to note that this result relies on the assumption that the regulator can only use one policy instrument to mitigate the two market failures.

None of the empirical studies in the review were able to directly observe the costs of specific types of regulation. They either used data on general costs of compliance with environmental policy, abatement costs or the timing of the policy to infer its effect on firms. Therefore, they could not estimate the effect of specific policy instruments on firms, only the effects of regulation in general. Theoretical papers, however, can usually isolate the effects of different instruments. This means that empirical papers and theoretical papers often approach the problem in two different ways, both of which provide valuable insights. Empirical papers study the relationship between a potentially complex system of environmental regulation and a 
dynamic market structure. Theoretical papers usually study the relationship between specific types of regulation and well-defined market structures.

Market structure and environmental policy can influence each other in many different ways. The optimal environmental regulation depends on market structure and regulation can change, and often increase, concentration in an industry. Researchers who study environmental policy under imperfect competition often recommend that policy makers take into account these sometimes unexpected ways in which market structure can influence and be influenced by regulation. 


\section{REFERENCES}

Bailey, J. B., \& Thomas, D. W. (2017). Regulating away competition: The effect of regulation on entrepreneurship and employment. Journal of Regulatory Economics, 52(3), 237-254. doi:http://dx.doi.org.ep.bib.mdh.se/10.1007/s11149-017-9343-9

Becker, R. A., Pasurka, C., \& Shadbegian, R. J. (2013). Do environmental regulations disproportionately affect small businesses? Evidence from the pollution abatement costs and expenditures survey. Journal of Environmental Economics and Management, 66(3), 523538.

Conrad, K., \& Wang, J. (1993). The effect of emission taxes and abatement subsidies on market structure. International Journal of Industrial Organization, 11(4), 499-518.

Coria, J., \& Kyriakopoulou, E. (2018). Environmental policy, technology adoption and the size distribution of firms. Energy Economics, 72, 470-485.

Espínola-Arredondo, A., Munoz-Garcia, F., \& Liu, B. (2019). Strategic emission fees: Using green technology to deter entry. Journal of Industry, Competition and Trade, 19(2), 313-349.

Helland, E., \& Matsuno, M. (2003). Pollution abatement as a barrier to entry. Journal of Regulatory Economics, 24(2), 243-259

Lieb, C.M. (2004). The environmental kuznets curve and flow versus stock pollution: The neglect of future damages. Environmental and Resource Economics, 29(4), 483-506.

Lin, P., \& Pang, Y. (2020). Command-and-control regulation, incentive for pollution abatement, and market structure. Journal of Regulatory Economics, 57(2), 159-180.

Martín-Herrán, G., \& Rubio, S. J. (2018). Optimal environmental policy for a polluting monopoly with abatement costs: Taxes versus standards. Environmental Modeling \& Assessment, 23(6), 671-689. doi:http://dx.doi.org.ep.bib.mdh.se/10.1007/s10666-018-9602$\mathrm{x}$

Montero, J. (2002). Market structure and environmental innovation. Journal of Applied Economics, 5(2), 293-325.

Phaneuf, D. J., \& Requate, T. (2017). A course in environmental economics: theory, policy, and practice. Cambridge University Press.

Reichenbach, J., \& Requate, T. (2013). Potential anti-competitive effects of emission permit markets - A survey on theoretical findings and evidence -. Jahrbuch Für Wirtschaftswissenschaften, 64(3), 271-291. 
Runkel, M. (2004). Optimal emissions taxation under imperfect competition in a durable good industry. Bulletin of Economic Research, 56(2), 115-132.

Ryan, S. P. (2012). The costs of environmental regulation in a concentrated industry. Econometrica, 80(3), 1019-1061.

Schoonbeek, L., \& de Vries, F.,P. (2009). Environmental taxes and industry monopolization. Journal of Regulatory Economics, 36(1), 94-106.

Sumner, J., Bird, L., \& Dobos, H. (2011). Carbon taxes: A review of experience and policy design considerations. Climate Policy, 11(2), 922-943. 


\section{क \\ MÄLARDALEN UNIVERSITY SWEDEN}

P.O. Box 883, SE-721 23 Västerås, Sweden Phone: +46 21101300 P.O. Box 325, SE-631 05 Eskilstuna, Sweden Phone: +46 16153600 E-mail: info@mdh.se Webb: www.mdh.se 